field covered. Seven chapters cover procedures connected with disorders of the main systems. All are good, but the section on the nervous system might have been expanded to include tests of vestibular and auditory function. Special sections on clinical radiology, the liver, blood transfusion and the treatment of water and salt depletion will be welcomed.

The final chapter presents a miscellany of valuable information including the principles of dietetics and the technique of special procedures such as joint aspiration. Lists of normal values and conversion tables will be found useful, and those who possess a copy of this book will no longer be tormented by times and dates relating to infectious fevers; they will convert milligrams per cent. to milliequivalents in a twinkling, and they will remain calm and unharassed by the vulgar fractions of pharmacopeial dosage, which tax even the best memories.

Throughout the volume the author and his colleagues have followed an original and sound plan; the rationale of a particular procedure is first approached from a physiological angle. This is followed by a brief description of the apparatus required and the technique employed. The final and most important paragraph deals with the interpretation of results. Instructions are clear and precise, but occasionally they suffer from the effects of multiple authorship and are contradictory (e.g. pp. 12, 123).

This book is destined for a long and useful career. As a guide to medical students it should prove invaluable but, in meeting the needs of the doctor engaged in modern hospital and general practice, it has few equals and no superior in this country today.

D.S.L.

\section{OCCUPATIONAL EYE DISEASES AND INJURIES}

By Joseph Minton, F.R.C.S. Pp. viii +184 , with 24. illustrations. London: William Heinemann. I949. 2 Is.

This book is designed to provide ophthalmologists, industrial medical officers and nursing sisters with a handbook covering the essential clinical features of the industrial hazards to which the visual apparatus is subject and the common visual problems which arise in the selection of industrial operatives. It also aims to bring home to ophthalmologists the importance of occupation as an etiological factor in ocular disease.

The book falls into three parts. The first deals with occupational injuries-mechanical, chemical and those due to radiant energy - and diseasesconjunctivitis, keratitis and the effects of various industrial solvents and poisons, and miners' nystagmus. The medico-legal problems which these various accidents arise are illustrated by case reports. The second part deals with the selection of personnel-the visual standards required for ordinary and special jobs, and the problems of the one-eyed, the blind and the partially-blind person Thirdly are two chapters on environment-lighting and colour schemes in industry and some problems of colour vision. There are two final chapters on protection of the eyes.

The section on mechanical injuries is largely con $\stackrel{?}{=}$ cerned with first-aid diagnosis and treatment though the author's views on more specialized methods of treatment are outlined. The remainder of the books from chemical injuries onwards is a fund of in $-\bar{Q}$ formation to ophthalmologists on aspects of theiro speciality of which many of them know little. I $t^{\prime}$ is most readable, excellently illustrated, and each $\overrightarrow{0}$ chapter is provided with a bibliography. A veryminor point for criticism is the frequency withw which the first person singular recurs in the text.

The book is an interesting and valuable addition to ophthalmic textbooks, and is the only one of its? kind in the English language.

A.L.

DISEASES OF THE NOSE AND THROAT

By Sir St. Clair Thomson, M.D., F.R.C.P.o F.R.C.S., Ll.D., and V. E. NEGUS, M.S., F.R.C.S. 5th Edition. Pp. xix + 1004, with 369 illustrations and 43 plates. London: Cassell \& Co. 1948. 70s.

This is not just another edition of this wellknown book. It represents a milestone in British laryngology, for during its preparation the origing author died, and although he had done much un the adverse conditions of war, the final preparation was left to his co-author. Negus is, indeed, as worthy successor, but he has had to enlist the aid of a number of colleagues owing to the rapid expansion of the subject and its closer association witho other branches of medicine and surgery, each more highly technical than at the time of publication ofô the last edition.

Thus, there have been considerable changes in parts of the book, although the general scheme re-0 mains much the same, and details of operative procedures are no longer relegated to a special 3 . chapter at the end but are appropriately includedoin the section dealing with the condition for which 3 . they are most frequently performed. The section on therapeutics now includes an account of sul- $\frac{3}{3}$ phonamide and antibiotic therapy, in which the inadvisability of administering these powerfulo agents for trivial conditions is rightly stressed. D There is an account of hormone and vitamin therapy, and also an article on irradiation in the treatment of new growths, where the relative merits. of surgery and other methods of treatment are $\mathrm{O}$ discussed. The classification of the blood diseases N has been brought up to date, and the relevant ${ }^{\omega}$ pathology described. A new section on the physiology of the nose serves to remind us of the importance of conservation of the nasal mucosa, $\mathbb{\Phi}$ whilst the section on nasal allergy has been expanded? and does much to clarify the situation, without 0 denying the complexity of the subject.

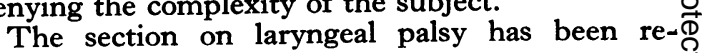

